\title{
Pudendal Neurectomy in Management of Neurogenic Bladder in Myelomeningocele
}

\author{
GORDON STARK \\ From the Department of Child Life and Health, University of Edinburgh
}

In a recent paper, good correlation was shown between the nature of the bladder disorder and the neurological picture in infants and young children suffering from myelomeningoceles (Stark, 1968). According to the function of the 2 nd-4th sacral segments on clinical examination of the lower limbs, patients could be classified into 4 groups (Fig. 1). Those in Group A (at least one leg neurologically normal) proved to have normal bladder function. Conversely, patients in Group D (flaccid paraplegia below S1) had inert bladders with no detrusor activity. Children with either incomplete voluntary activity (Group B) or purely reflex function (Group C) in S2-4 proved in $90 \%$ of cases to have an active bladder detrusor. In more than half of these, however, bladder emptying was highly inefficient. As this appeared to be due to failure of the striated external sphincter to relax during detrusor contractions, it was suggested

Received April 14, 1969. that pudendal neurectomy might be useful in relieving outflow obstruction.

Bilateral pudendal neurectomy was carried out on 12 such children during the first 6 months of 1968.

This paper is intended to describe the results and evaluate the place of this operation.

\section{Patients and Method of Assessment}

The 12 patients ( 7 girls and 5 boys) all suffered from open myelomeningoceles which, with one exception, had been closed in the first $\mathbf{4 8}$ hours of life. The mean age at the time of operation was 2 years 9 months (10 months to 8 years 2 months). One child had 2 operations (Case 2). Before pudendal neurectomy, all had been subjected to careful neurological examination and assessment of bladder function as previously described (Stark, 1968). This included pressure studies and cysto-urethrography carried out through suprapubic catheters, concentric needle electrode electromyography of the anal sphincter and pelvic floor, and measurement of residual urine volumes.
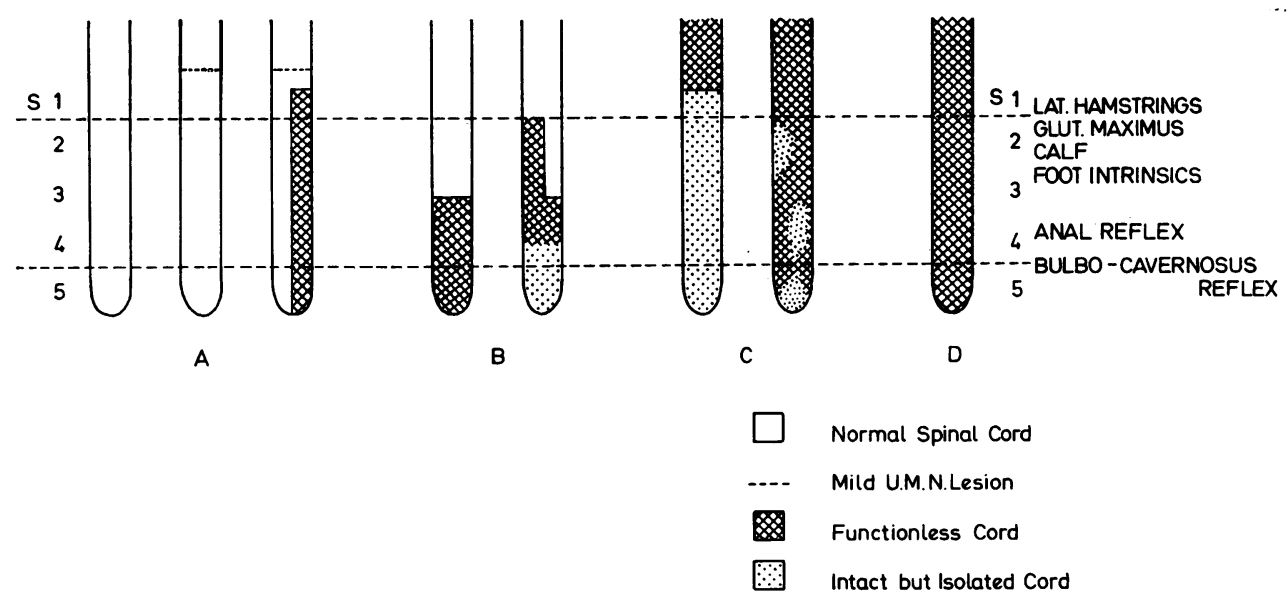

FIG. 1.-Neurological grouping of patients. Reproduced from: The pathophysiology of the bladder in myelomeningocele and its correlation with the neurological picture, by Gordon Stark. (Develop. Med. Child Neurol., 10, Suppl. No. 16, 77). 


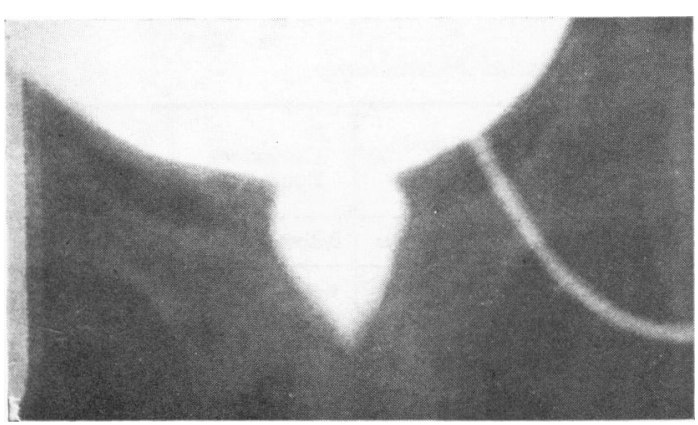

Fig. 2.-Cystographic appearance of obstruction at external sphincter (Case 1).

The following criteria were considered to indicate bladder outflow obstruction due to failure of relaxation of the external sphincter:

(1) Large residual volume ( $>25 \mathrm{ml}$. even after manual expression).

(2) Cystographic evidence of obstruction at external sphincter level (Fig. 2).

(3) Electromyographic evidence of at least moderate motor unit activity in the striated muscle of the pelvic floor and/or anal sphincter (Fig. 3).

Renal function as measured by intravenous pyelography and radio-hippuran renography was normal in all cases, but there was delay in the excretory phase of the renogram in all but 3 .

\section{Technique of Operation}

With the patient in the prone jack-knife position, one pudendal nerve (or its terminal branches) was identified at a point which varied between the ischial spine and the pudendal canal. The nerve was divided between ligatures distal to the origin of the inferior haemorrhoidal nerve which was spared. The procedure was then repeated on the opposite side.

After the operation, patients were nursed in the prone position until sutures were removed on the tenth day. Wound infection developed in one child but otherwise recovery was rapid, and more recently children have been discharged home after 3 to 4 days to return for removal of sutures as out-patients.

Full assessment of bladder function was repeated a few weeks after operation.

\section{Results}

The main pre- and post-operative findings are summarized in the Table and Fig. 4.

After pudendal neurectomy, the following changes were observed.

Intravesical pressure. The pattern of detrusor activity was unchanged, but in 9 cases the whole pressure tracing was at a lower level (Fig. 5) suggesting a reduction in outflow resistance. Before operation, in only 3 patients were the peaks of voiding contractions less than $40 \mathrm{~mm}$. $\mathrm{Hg}$, i.e. in the normal range (King, Mellens, and White,

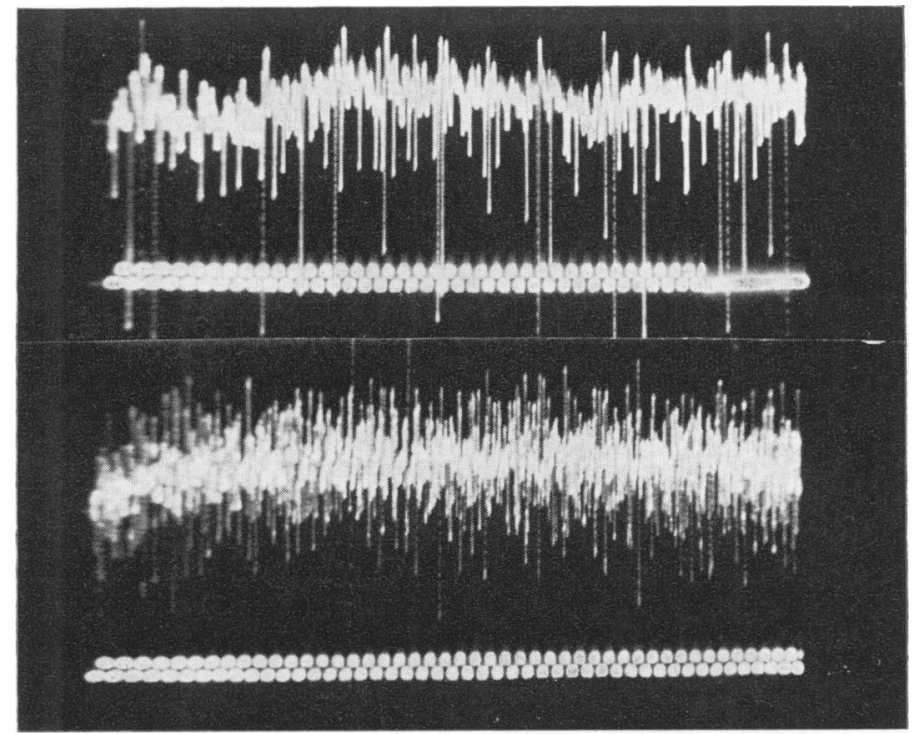

FIG. 3.-Range of EMG activity in pelvic floor: (a) incomplete interference pattern; (b) full interference pattern. Voltage calibration below records: $100 \mu \mathrm{V}$. Sweep duration $1 \mathrm{sec}$. 
TABLE

Summary of Findings Before and After Pudendal Neurectomy

\begin{tabular}{|c|c|c|c|c|c|c|c|c|c|c|c|c|c|c|c|}
\hline \multirow[t]{2}{*}{$\begin{array}{l}\text { Case } \\
\text { No. }\end{array}$} & \multirow[t]{2}{*}{ Sex } & \multirow{2}{*}{$\begin{array}{l}\text { Neuro- } \\
\text { logical } \\
\text { Group }\end{array}$} & \multirow{2}{*}{$\begin{array}{l}\text { Age at } \\
\text { Opera- } \\
\text { tion (yr.) }\end{array}$} & \multicolumn{2}{|c|}{$\begin{array}{c}\text { Anal } \\
\text { Reflex }\end{array}$} & \multicolumn{2}{|c|}{$\begin{array}{c}\text { Detrusor } \\
\text { Peaks } \\
(\mathbf{m m} . \mathbf{H g})\end{array}$} & \multicolumn{2}{|c|}{$\begin{array}{c}\text { Expression } \\
\text { Pressure } \\
(\mathrm{mm} . \mathrm{Hg})\end{array}$} & \multicolumn{2}{|c|}{$\begin{array}{c}\text { Residual } \\
\text { Volume } \\
\text { (ml.) }\end{array}$} & \multicolumn{2}{|c|}{$\begin{array}{l}\text { Cystogram } \\
\text { Funnelling }\end{array}$} & \multicolumn{2}{|c|}{$\begin{array}{c}\text { Cystogram } \\
\text { Reflux }\end{array}$} \\
\hline & & & & Before & After & Before & After & Before & After & Before & After & Before & After & Before & After \\
\hline $\begin{array}{l}1 \\
2\end{array}$ & $\begin{array}{c}F \\
M\end{array}$ & $\begin{array}{l}\text { C } \\
\text { C }\end{array}$ & $4^{\frac{11}{12}}$ & $\begin{array}{l}++ \\
++\end{array}$ & $\begin{array}{l}++ \\
++\end{array}$ & $\begin{array}{l}65-75 \\
70-80\end{array}$ & $\begin{array}{l}30-40 \\
55-60\end{array}$ & $\begin{array}{l}80 \\
90\end{array}$ & $\begin{array}{c}40 \\
75-85\end{array}$ & $\begin{array}{l}34 \\
95\end{array}$ & $\begin{array}{r}17 \\
256\end{array}$ & $\begin{array}{c}+++ \\
++\end{array}$ & $\begin{array}{c}+++ \\
++\end{array}$ & 二 & $=$ \\
\hline & & & $4 \frac{11}{12}$ & ++ & + & $55-60$ & 50 & $75-85$ & $>90$ & 256 & 295 & ++ & ++ & - & - \\
\hline 3 & $\mathbf{M}$ & C & $8_{12}^{2}$ & ++ & ++ & 60 & $25-30$ & $80-90$ & 35 & 122 & 10 & ++ & 一 & - & - \\
\hline 4 & F & B & $\begin{array}{l}12 \\
1 \frac{3}{12}\end{array}$ & - & - & 60 & $20-25$ & $60-70$ & 40 & 78 & 20 & ++ & - & - & - \\
\hline $\begin{array}{l}5 \\
6\end{array}$ & $\underset{F}{\mathbf{M}}$ & $\begin{array}{l}\mathbf{C} \\
\mathbf{B}\end{array}$ & $\begin{array}{l}2^{12} \\
3^{32}\end{array}$ & $\begin{array}{l}++ \\
+t\end{array}$ & $\overrightarrow{+t}$ & $45-55$ & $35-40$ & $\begin{array}{l}60 \\
50\end{array}$ & 40 & $\begin{array}{l}65 \\
35\end{array}$ & 18 & $\stackrel{+}{+}+$ & 二 & $\bar{t}$ & $=$ \\
\hline & & & & & & & & 30 & & & & $+7+$ & & $\begin{array}{c}\text { bi- } \\
\text { lateral }\end{array}$ & \\
\hline 7 & $\mathrm{~F}$ & C & $\frac{10}{12}$ & ++ & - & $40-45$ & $25-30$ & $60-80$ & $30-40$ & 28 & 2 & ++ & + & - & - \\
\hline 8 & $\mathbf{M}$ & D & $\frac{1}{1} \frac{1}{2}$ & - & - & $20-30$ & $20-30$ & $60-80$ & $40-60$ & 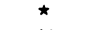 & 10 & +++ & +++ & - & - \\
\hline 9 & $\mathbf{F}$ & B & 2 & ++ & ++ & 55 & 28 & $>90$ & $40-50$ & 60 & 30 & +++ & 一 & - & - \\
\hline 10 & $\mathbf{F}$ & B & 1 & ++ & ++ & $30-35$ & $30-35$ & $50-60$ & $t$ & 50 & 10 & ++ & + & - & - \\
\hline 11 & $\mathbf{F}$ & C & $4 \frac{1}{12}$ & ++ & ++ & $50-65$ & $60-70$ & $t$ & $t$ & 88 & 70 & +++ & +++ & - & - \\
\hline 12 & $\mathbf{M}$ & C & $41^{1} 2$ & ++ & ++ & $85-90$ & $60-70$ & $t$ & $t$ & 25 & 19 & +++ & +++ & - & \\
\hline
\end{tabular}

1965); after operation, however, voiding contractions exceeded $40 \mathrm{~mm}$. $\mathrm{Hg}$ in only 3 patients.

Outflow resistance. In several patients there was a gush of urine in theatre as soon as the pudendal nerves were divided and the increased ease of manual expression was usually noticed by nurses, and later, by mothers. With the exception of Case 2, the intravesical pressure required to achieve voiding by manual expression was significantly reduced in all cases for whom accurate figures were available.

\section{EFFECTS OF BLLATERAL PUDENDAL NEURECTOMY}

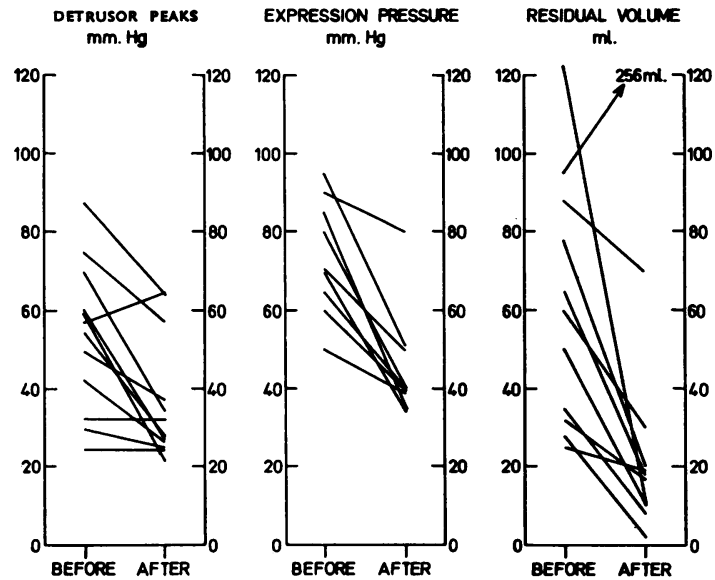

FIG. 4.-Results of operation.
Residual volume. This is the most valid measure of the adequacy of bladder drainage. On this basis only 2 patients (Cases 2 and 11) failed to improve. In Case 8 , the residual volume could not be measured before operation as the urethral catheter would not pass $7.5 \mathrm{~cm}$., but after operation it was only $10 \mathrm{ml}$. In the remaining 9 cases, the mean residual volume fell from $55 \cdot 2 \mathrm{ml}$. $\pm \mathrm{SD} 30.3$ to $15 \cdot 0 \mathrm{ml} . \pm \mathrm{SD} 7 \cdot 8$; a reduction of $73 \%$.

Cystogram. In 7 patients there was an alteration in the configuration of the bladder outlet, viz. relief of constriction at external sphincter level and reduction in funnelling of the posterior urethra (Fig. 6); in 4, this change was striking (in one, ureteric reflux also disappeared) while in 3 it was slight. In 5 cases there was no significant change though the other parameters showed improvement in 3 of them.

Undesirable effects. In one child the anal reflex which was brisk before operation was temporarily lost but later returned. In another (Case 2) the anal reflex became less brisk and there was an increase in faecal soiling.

The following brief histories illustrate a successful outcome (Case 3) and failure (Case 2).

\section{Case Reports}

Case 3. This 8-year-old boy with an epithelialized thoraco-lumbar myelomeningocele had no voluntary movement below $\mathrm{T} 12$ on the right, $\mathrm{L} 3$ on the left. There was, however, preservation of reflex activity in 


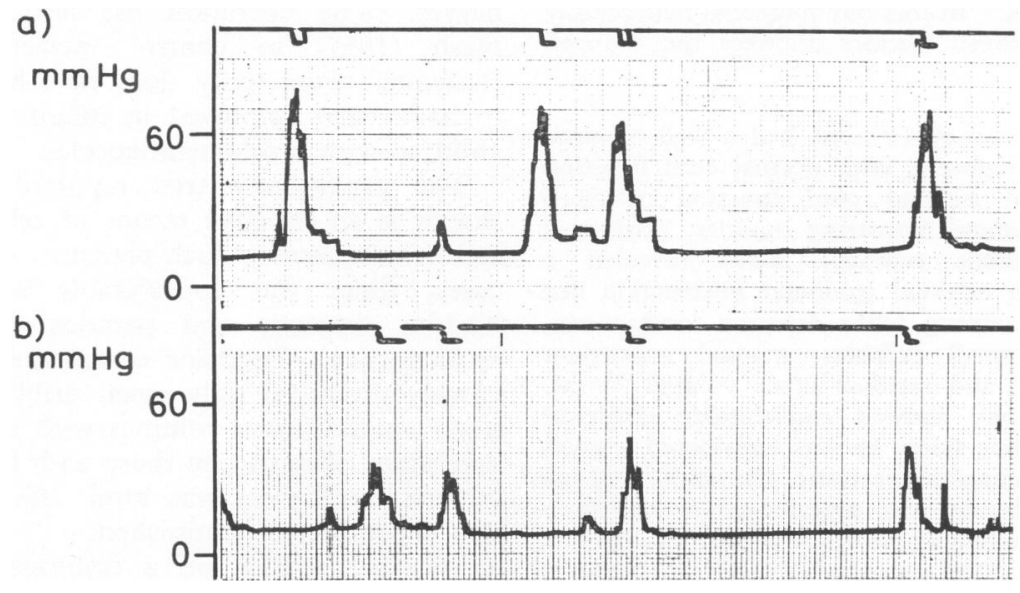

Fig. 5.-Case 1. Cystometrogram (a) before and (b) after operation.

S3-5 (brisk anal reflex and toe flexion on perianal stimulation). He had a history of chronic bladder distension with overflow dribbling, and while on the waiting list for assessment was admitted with acute retention. On examination, the bladder was grossly distended, manual expression was ineffective, and he was relieved of $>800 \mathrm{ml}$. urine by catheter. After a period of catheter drainage, pressure studies showed a reflex bladder with strong detrusor activity; contractions produced pressures up to $70 \mathrm{~mm}$. $\mathrm{Hg}$, but voided only small dribbles. Abdominal straining $(60 \mathrm{~mm}$. $\mathrm{Hg}$ ) was ineffective and the residual volume was $122 \mathrm{ml}$. On cystography the bladder was trabeculated with funnelling of the posterior urethra but no ureteric reflux. Electromyography showed significant motor unit activity in the anal sphincter, pelvic floor, and foot intrinsics but complete denervation in all other muscles innervated below T12 on the right, T11 on the left. IVP was normal; radio-hippuran renogram showed normal vascular and secretory phases but bilateral delay in excretion. After pudendal neurectomy 17 days after admission, the indwelling catheter could be removed for the first time. Reflex voiding occurred of 100-150 ml. despite considerable reduction in intravesical pressures. When detrusor contractions were supplemented by abdominal straining, residual volume was only $10 \mathrm{ml}$. He is now on a regimen of 2-hourly voiding and the small intermittent dribbles are collected
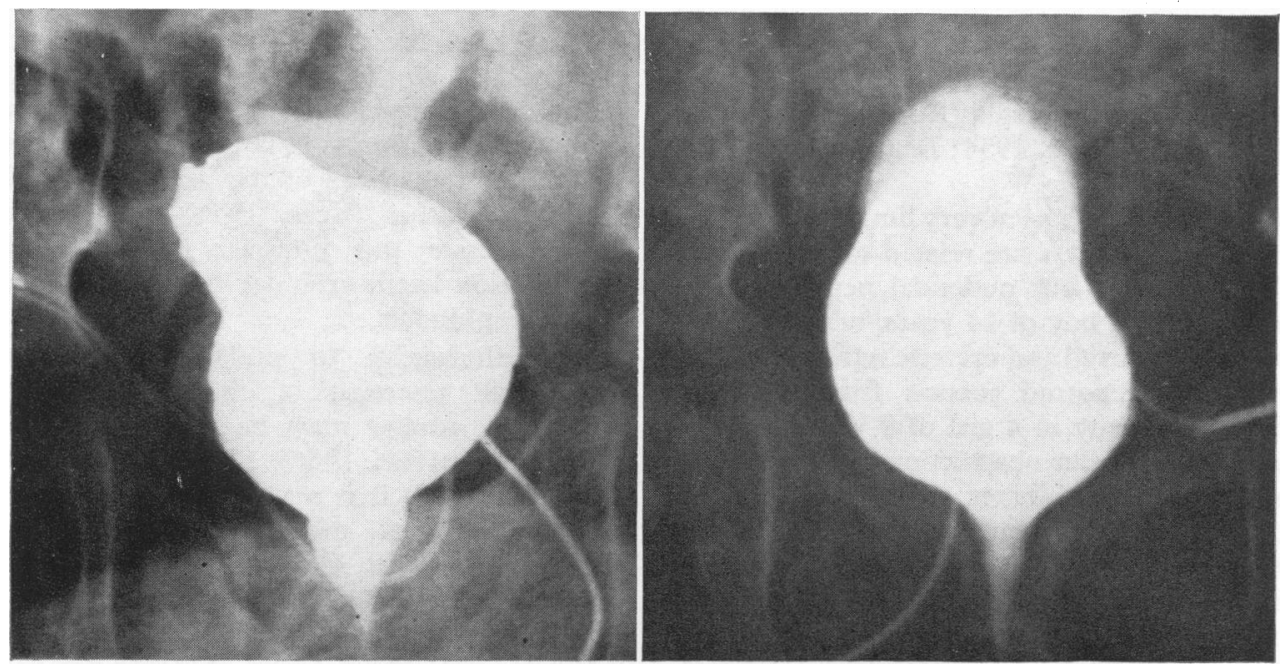

FIG. 6.-Case 9. Cystogram (a) before and (b) after operation. 
in a portable urinal. In this boy pudendal neurectomy has not only improved bladder drainage but reduced incontinence.

Case 2. This boy of $4 \frac{1}{2}$ years had a well-repaired lumbar myelomeningocele, with normal cord function down to L4 and isolated cord function in S1-5 (spastic calf and lateral hamstring muscles, brisk anal and bulbo-cavernosus reflexes). $X$-ray revealed a large bladder with external sphincter obstruction but no reflux; despite strong reflex detrusor contractions, voiding was in small dribbles, manual expression almost impossible, and residual urine volume $95 \mathrm{ml}$. As electromyography showed considerable electrical activity in the pelvic floor, he was considered a good candidate for pudendal neurectomy. On account of his obesity, some difficulty was experienced at operation in locating the pudendal nerves and he developed a wound infection. After recovery intravesical pressures and resistance to bladder expression were still high and the residual volume no less than $256 \mathrm{ml}$. As electromyography was unchanged, it was decided to repeat the operation and this was done 3 months later, when each pudendal nerve was identified as a leash of at least four branches; these were divided but the inferior haemorrhoidal nerves preserved. Again, though the anal reflex became sluggish, there was no significant change in bladder function and electrical activity persisted in the pelvic floor. As the bladder could not be expressed and residual urine was nearly $300 \mathrm{ml}$. external sphincterotomy was carried out (Mr. D. Innes Williams); residual volume fell to $40 \mathrm{ml}$. He is now wearing a Chailey urinal and attends a normal school.

\section{Discussion}

It is 70 years since the first description of pudendal neurectomy as a means of correcting imbalance between sphincter and detrusor in cases of neurogenic bladder (Rochet, 1899). Since then it has become an established procedure in management of adult traumatic paraplegia (Ross and Damanski, 1953; Bors and Comarr, 1954; Band, 1956; Hardy, 1956; Tasker, 1961).

Its use, however, has been very limited in children whose bladder disorders are related to spina bifida. Band (1956) carried out pudendal neurectomy on one such patient, a boy of 14 years, whose bladder drainage was improved and ureteric reflux abolished. Roberts (1962) reported success from unilateral pudendal neurectomy in a girl of 9 years suffering from external sphincter obstruction. Smart (1965) diagnosed external sphincter spasm in 3 patients aged 13, 14, and 19 years: unilateral pudendal neurectomy abolished residual urine in 2 and reduced it considerably in the third, with, in addition, diminution of incontinence. Smith (1965) found that the bladders of four children were more easily expressed after crushing of the pudendal nerves. The operation has also been used by Nash (1957) to control intractable priapism. Pudendal neurectomy does not, however, appear to have been employed in infants or very young children with myelomeningoceles.

The preliminary trial reported here suggests that it is an effective means of relieving 'external sphincter spasm' in such patients. In 10 out of 12 cases, there was considerable improvement in bladder drainage and paradoxical reduction in incontinence. Detrusor contractions, which previously produced only small dribbles, post-operatively voided larger volumes with less intermittent dribbling; similarly, in those with feeble detrusors, manual expression was more effective and overflow incontinence diminished.

Success depends on a combination of careful selection and meticulous surgical technique. There must be evidence not only of obstruction at the level of the external sphincter but of activity in the muscle itself as judged by electromyography or preservation of anal and bulbo-cavernosus reflexes. A recent case illustrates this point: the cystogram of this 4-year-old boy with spina bifida suggested sphincteric obstruction (Fig. 7); there was, however, no clinically detectable reflex activity in the sacral cord, and electromyography of the pelvic floor showed almost complete denervation. As this seemed anomalous, he was cystoscoped: posterior urethral valves were found and later successfully resected. This child would clearly not have responded to pudendal neurectomy.

Identification of the pudendal nerve and its branches may be difficult in small children especially if the nerve divides unusually high. This seems to have been the explanation for the 2 failures in this series, as both still showed considerable electrical activity in the pelvic floor musculature following operation. It is possible that section of the nerve at the level of the ischial spine (Tasker, 1961) or sacrum (Ross, 1956) might have been more effective; this, however, involves sacrifice of the inferior haemorrhoidal nerve which supplies the anal sphincter.

The alternative to pudendal neurectomy is endoscopic resection of the external sphincter which, in adults, may be simpler and equally effective (Smythe, 1966). However, as noted by Johnston (1968) it is a very difficult procedure in infancy; perineal urethrotomy is necessary in boys and there is a risk of later stricture from post-operative fibrosis.

Though the place of pudendal neurectomy is still tentative, it is likely to be of particular value for relief of outflow obstruction in the first few years 


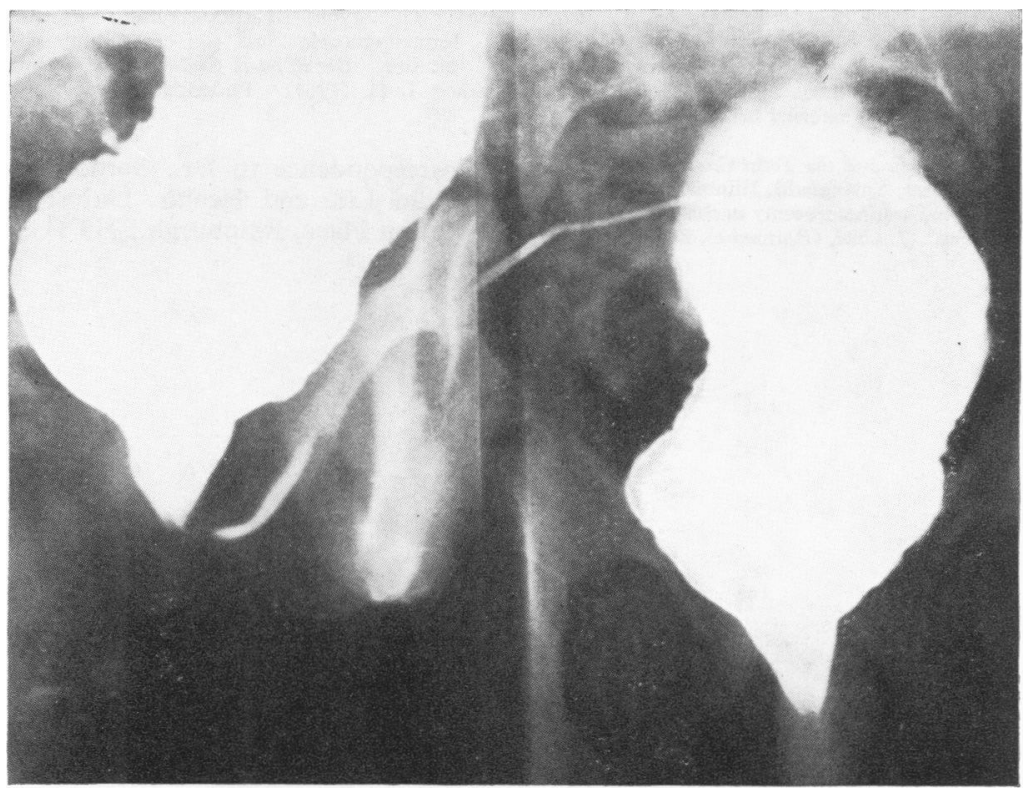

FIG. 7.-Cystogram during and after voiding (posterior urethral valves).

of life. Free drainage having been secured, bladder expression is more effective, and between the ages of 3 and 4 years boys can be fitted with portable urinals. In many cases, especially among girls, diversion will later be required for control of incontinence; this can, however, be carried out as an elective procedure as school age approaches and should be necessary less often as a salvage procedure to drain irreparably damaged upper urinary tracts. The sheet anchor of such a programme is full assessment of bladder function within the first 3 months of life. Though often recommended, an IVP alone is of limited value at this stage and may give a false sense of security: as damage to the upper urinary tract is secondary to bladder decompensation, the most useful single test is a cystogram with measurement of residual volume.

\section{Summary}

Failure of relaxation of the external urethral sphincter is a common cause of bladder decompensation in children suffering from myelomeningoceles.

In 10 out of 12 such patients, bilateral pudendal neurectomy was successful in relieving bladder outflow obstruction. The importance of careful selection for operation and of meticulous technique is emphasized.

Full assessment of bladder function within 3 months of birth is recommended in all infants with myelomeningoceles so that bladder balance can be restored before upper urinary tract damage occurs.

I am particularly grateful to Miss R. M. I. Mackay and Mr. F. H. Robarts for their willingness to carry out these operations and generous advice during the preparation of this report. I am indebted to Miss J. Mander and Mrs. J. Davidson for patient nursing help during the investigations and to Miss $U$. Burnet for secretarial assistance. Fig. 1 is reproduced by kind permission of the Editor of Developmental Medicine and Child Neurology.

This work was supported by the National Fund for Research into Crippling Diseases.

\section{REFERENCES}

Band, D. (1956). Lesions of the bladder in incomplete paraplegia. Brit. F. Urol., 28, 37.

Bors, E., and Comarr, A. B. (1954). Effect of pudendal nerve operations on the neurogenic bladder. $f$. Urol. (Baltimore), 72, 666.

Hardy, A. G. (1956). Some aspects of the management of the bladder in traumatic paraplegia. Brit. F. Urol., 28, 53.

Johnston, J. H. (1968). Endoscopic techniques. In Paediatric Urology, p. 544. Ed. by D. Innes Williams. Butterworths, London.

King, L. R., Mellens, H. Z., and White, H. (1965). Measurement of the intravesical pressure during voiding. Invest. Urol., 2, 303.

Nash, D. F. E. (1957). Congenital spinal palsy-the management of incontinence. Ann. roy. Coll. Surg. Engl., 20, 349.

Roberts, J. B. M. (1962). Spina bifida and the urinary tract. ibid., 31, 69.

Rochet, V. (1899). Résection de la branche périnéale des nerfs honteux internes dans certaines affections spasmodiques de l'urètre et du périnée. Arch. provinciales de chirurgie, 312, 321. 
Ross, J. C. (1956). Treatment of the bladder in paraplegia. Brit. f. Urol., 28, 14.

, and Damanski, M. (1953). Pudendal neurectomy in the treatment of the bladder in spinal injury. ibid., 25, 45.

Smart, P. J. G. (1965). Spasm of the external urethral sphincter in spina bifida. ibid., 37, 574.

Smith, E. D. (1965). Spina Bifida and the Total Care of the Spinal Myelomeningocoele. Thomas, Springfield, Illinois.

Smythe, C. A. (1966). External sphincterotomy in the management of the neurogenic bladder. $f$. Urol. (Baltimore), 96, 310 .
Stark, G. (1968). Pathophysiology of the bladder in myelomeningocoele and its correlation with the neurological picture. Devel. Med. Child Neurol., suppl. 16, 76.

Tasker, J. H. (1961). Pudendal neurectomy. Brit. f. Urol., 33, 397.

Correspondence to Dr. Gordon Stark, Department of Child Life and Health, University of Edinburgh, 17 Hatton Place, Edinburgh EH9 1 UW. 